\title{
JUURNAL.RU
}

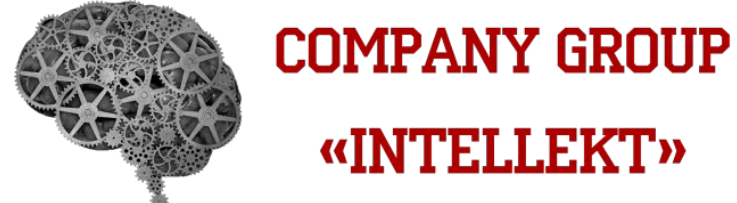

Ермолаева Н.В. Севастьянов Д.А. ВИТИ НИЯУ МИФИ Волгодонск, Россия

doi: 10.18411/lj2016-6-1-09

\section{Универсальный модуль для лабораторных работ на основе Arduino под управлением Android}

При покупке нового оборудования для физического практикума (осциллограф, или мультиметр), оплачивается датчик и вычислительное устройство, которое встроено в прибор. В настоящей работе мы предлагаем уменьшить стоимость физического оборудования,применив принцип «модульности»: использовать устройство, на основе платы Arduino, к которому присоединяются различные датчики физических величин, а в качестве устройства обработки данных применять смартфон на OC Android. Количество присоединяемых датчиков можно варьировать в зависимости от требований физической лаборатории. Причем точность измерений определяется выбороммодели датчиков и что важно, не зависит от модели смартфона.В учебном процессе предлагается использовать смартфоны учащихся.

Применение собственного смартфона при выполнении лабораторных работ по физике должно способствовать активизации познавательной деятельности и развитию учебной мотивации студентов, поскольку обучение с использованием мобильных устройств не отделено от реальной жизни $[1,2]$.

Принцип действия предлагаемого нами устройства следующий. При осуществлении замеров информация от датчиков поступает на плату Arduino. Далее осуществляется обработка информации на Arduino и еe отправка на устройство Android (смартфон) через USB- кабель. Следующий этап - обработка 
информации смартфоном с помощью специальных предварительно на нем установленных программ. Заключительный этап - графическое отображение информации на экране смартфона. Внешний вид устройства, подключенного к смартфону, представлен на рис. 1. На плате управления (1) установлены кнопки включения/выключения омметра (2), вольтметра (3) и цифровой датчик DHT11 (4), датчик влажности и температуры DHT11 (8) и щупы вольтметра (7). Информация от датчиков передается на плату Arduino (5). Связь со смартфоном осуществляется через USB кабель питания и обмена данными (6).

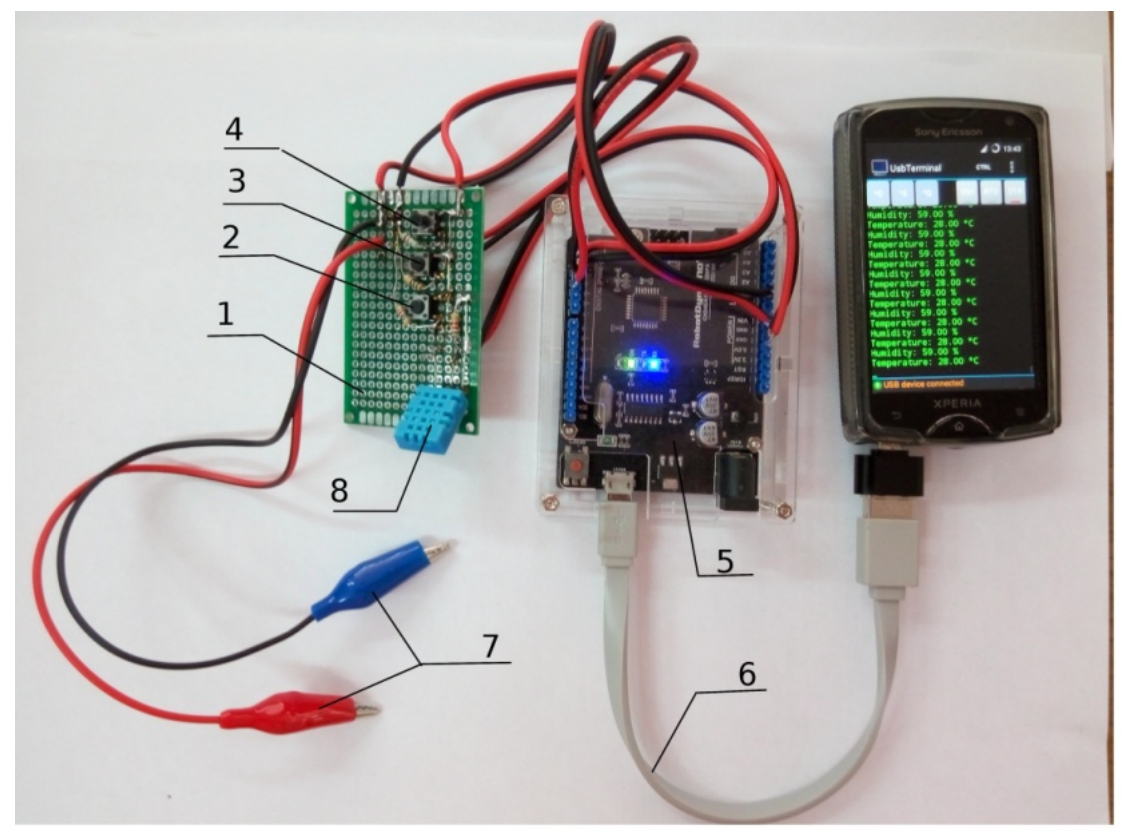

Рис.1 -Внешний вид модуля для замера физических величин

В ходе проделанной работы было разработан измерительный модуль на плате Arduino формата UNO, расширяющее функциональные возможности смартфонов, работающих на операционной системе Android. Разработанное устройство позволяет измерять температуру, влажность воздуха, сопротивление резисторов и напряжение на низковольтных элементах цепи и выводить результаты измерений на экран смартфона. Погрешность измерений, полученных с помощью разработанного устройства, не превышает 5\%. 


\section{Литература:}

1. А.В. Кудрявцев Новые возможности использования мобильных устройств в учебном процессе ВУЗа. //Педагогическое образование в России.- 2015.№ 7.- C. 71-76.

1. 2.С.В. Лозовенко, А.А. Паутова.Использование смартфонов и планшетных компьютеров в учебном физическом эксперименте.//Школа будущего. 2014. - № 3. - c. 92-97. 